
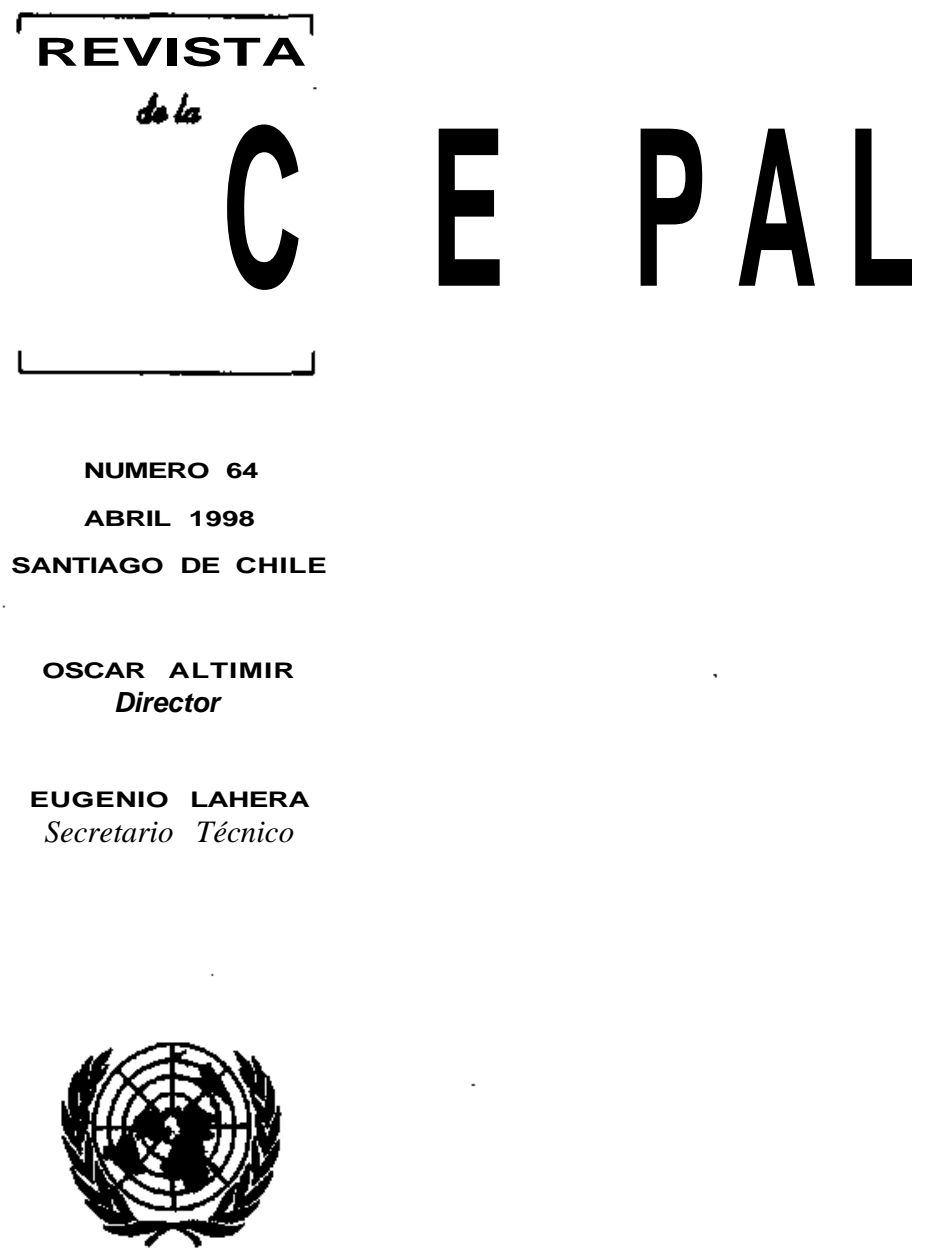

NACIONES UNIDAS 
Instituciones y crecimiento ¿Puede el capital humano ser un vínculo?

Nauro Campos y Jeffrey B. Nugent

Flujos de capital externo en América Latina y el Caribe en los años noventa: experiencias y políticas

Gunther Held y Raquel Szalachman

El Banco Central y la política macroeconómica de Chile en ios años noventa

Roberto Zahler

Política fiscal, ciclo y crecimiento

Ricardo Mariner

La convergencia hacia mejores prácticas productivas y de políticas: el acuerdo de la OMC sobre medidas de inversión vinculadas al comercio

Francisco Sercovich

Efectos para América Latina de la expansión de la Unión Europea

Peter Nunnenkamp

La dimensión Norte-Sur de las industrias de limpieza ambiental

y la difusión de tecnologías limpias

Jonathan R. Barton

La evolución del papel del Estado en la regulación del transporte terrestre

lan Thomson

Manejo integrado del recurso agua, con la perspectiva de los

Principios de Dublin

Miguel Solanes

Publicaciones recientes de la CEPAL 


\section{La convergencia hacia}

\section{mejores prácticas productivas \\ y de políticas: el acuerdo de \\ la OMC sobre medidas de \\ inversión vinculadas al comercio}

\section{Francisco Sercovich}

Jefe de Estudios de Políticas

de Desarrollo Industrial,

Organización de las

Naciones Unidas para el

Desarrollo Industrial

(ONUDI)
La experiencia internacional sugiere que no hay tal cosa como

la réplica y adopción de mejores prácticas industriales a escala universal. Lo que tiene lugar es una adaptación progresiva y recíproca entre prácticas externas y locales, en la cual los costos y tiempos de aprendizaje cuentan de manera esencial. El potencial de convergencia de políticas, prácticas e instituciones cuya realización se ve estimulada por el proceso de globalización, parece ser mayor en el orden macroeconómico que en el microeconómico. Este artículo examina primero estos temas de una manera general y luego explora algunos aspectos relevantes a la luz de los dilemas que confrontan los países de la Asociación de Naciones del Asia Sudoriental (ASEAN) en el cumplimiento del acuerdo de la Organización Mundial de Comercio (OMC) sobre las medidas en materia de inversión relacionadas con el comercio para el año 2000. Esta experiencia es especialmente valiosa para otras regiones en desarrollo, en especial América Latina y el Caribe, dadas las dificultades que derivan de la carrera contra el tiempo desatada para conciliar tales compromisos con objetivos de desarrollo nacional. 
I

\section{Introducción}

El proceso de globalización ha colocado el tema de la convergencia internacional de prácticas productivas, políticas e instituciones de lleno en la agenda del debate actual sobre la economía mundial. La adopción internacional de mejores prácticas de política, como las convenidas por un gran número de países miembros de la Organización Mundial de Comercio (OMC), parece ser cada vez más irresistible, y se espera que esto facilite una mayor nivelación del campo de juego en el mercado internacional. La introducción de plazos perentorios para adecuar las políticas nacionales a reglas uniformes y universales confiere al tema un sentido de urgencia y elevada prioridad, en especial dado su fuerte impacto sobre el proceso de desarrollo económico y social en los países en desarrollo y las ex economías de planificación centralizada.

La fuerza y aceleración del impulso hacia la convergencia de políticas parecen irrefrenables. De los 109 países en desarrollo y economías en transición que han emprendido programas sustantivos de reforma económica orientados al mercado, 75 lo han hecho a partir de 1989. Al mismo tiempo, 104 de tos 131 países miembros de la OMC son economías en desarrollo o en transición, en tanto que otras 28 -incluidas China, Rusia y la provincia de Taiwán- se encuentran negociando activamente su ingreso a la organización (Sercovich y otros, por publicarse, capítulo 2).

Estas cifras revelan una generalización del proceso de retiro del Estado como agente económico directo y una evolución hacia economías más abiertas y mercados más desregulados y competitivos. Sin embargo, esta constancia no debería inducir a trivializar el tema de la convergencia internacional de políticas, ni llevar a conclusiones prematuras sobre la pérdida de grados de libertad a nivel nacional (Sercovich y otros, por publicarse; De María y Campos y Sercovich, por publicarse).

Una versión preliminar de este artículo fue presentada en la $1^{\text {a }}$ Reunión del Foro Regional Ministerial sobre Industrialización (SELA, Caracas, 30 de julio y 1 de agosto de 1997). El autor agradece a M, de María y Campos, P. de Motta Veiga, R. Lavagna, S. Teitel, a un juez anónimo y, en especial, a J. Katz por sus comentarios, y a K.-Y. Nam por su asistencia. Ni la ONUDI ni los nombrados comparten necesariamente las opiniones aquí vertidas.
El Acuerdo de la OMC sobre las medidas en materia de inversiones relacionadas con el comercio (MIC) ${ }^{1}$ establece que, en el año 2000, los países en desarrollo (y en el 2002 los de menor desarrollo relativo) deberán eliminar de sus políticas hacia la inversión extranjera todas aquellas regulaciones que impongan condiciones relativas a las importaciones, exportaciones o balance de divisas, incluyendo las atinentes al contenido local.

Típicamente, tales regulaciones están inscritas en programas de desarrollo industrial con horizontes que van mucho más allá del año 2000 (como es el caso conspicuo de algunos países del Asia sudorienta]). Por consiguiente, cabe preguntarse qué situación se planteará una vez transcurridos los escasos dos años que faltan hasta entonces.

Puede anticiparse que esta situación dará lugar a diversos pedidos de excepción en la aplicación de los plazos por parte de países miembros y, a fortiori, de países que aún se encuentran negociando su ingreso a la OMC. Tales pedidos ya estaban en pleno proceso de incubación antes de la crisis de crecimiento que se inició en Tailandia a mediados de 1997 y luego se extendió a todo el Asia sudoriental y más allá, y que probablemente sean acicateados por ella. ${ }^{2}$ Los solicitantes harán lo posible por concretar los cambios de política

\footnotetext{
' Véase este Acuerdo en el Acta Final de la OMC (Marrakcsh, 1994), anexo $1 \mathrm{~A}$.

${ }^{2}$ La crisis de la segunda mitad de 1997 ha desatado dos fuerzas de sentido opuesto. Por un lado, la desaceleración de los planes de inversión por acumulación de inventarios y exceso de capacidad causará una dilación en el cumplimiento de los objetivos de las políticas nacionales y, con ello, fuertes presiones para extender los plazos de la OMC. Por el otro, la crisis también está contribuyendo a moderar objetivos ambiciosos de modernización y desarrollo tecnológico. Con todo, es improbable que el resultado neto favorezca los también ambiciosos objetivos de la OMC 2000 en materia de convergencia. Hay, en este sentido, una gran variedad de situaciones. Por un lado, los países del Asia oriental se verán confrontados por primera vez con el problema del desempleo (en ausencia de efectivas redes de seguridad social). Se estima que la dramática reducción de las tasas de crecimiento causará 2 millones de desocupados en Tailandia, 1.5 millones en la República de Corea y 200000 en Malasia. Este último país ha comenzado ya a revertir su política de avance generalizado hacia actividades manufactureras con uso intensivo de capital y tecnología: ahora da la bienvenida a operaciones manufactureras de propiedad extranjera que hacen uso intensivo de mano de obra, en la medida en que estén dirigidas a abastecer mercados externos (véase el anuncio oficial del Primer Ministro, Dr. Mahathir, en The Star, 1997). Si bien en toda la subregión se están introduciendo enérgicas medidas de austeridad fis-
} 
en cuestión una vez que las actividades promovidas hayan alcanzado una competitividad sustentable tras el necesario período de aprendizaje, no antes. No parece pues arriesgado vaticinar un resurgimiento de los debates sobre la legitimidad de las formas y tiempos de aplicación del argumento de la industria incipiente, dado que la vigencia del argumento mismo no está en discusión.

Si se acentúa aún más la falta de sincronía que se observa en la convergencia de políticas, particularmente en una perspectiva interregional e intersectorial $y$, como reza el acuerdo, se van a tener en cuenta dificultades particulares por la vía de la excepción, podrían verse afectadas la necesaria universalidad en la aplicación de las reglas y la buscada nivelación del campo de juego. ${ }^{3}$

Esta cuestión evoca otra de carácter más general: ¿es la adhesión universal y perentoria a reglas uniformes la mejor manera de propender a la nivelación del campo de juego en todos los casos? Más precisamente: ¿es posible definir reglas universales de mejor prác- tica internacional que puedan ser asimiladas de manera uniforme, sin costo neto descontado y en pocos años por todos los países, cualesquiera sean su grado de desarrollo y sus especificidades nacionales? Y, finalmente: ¿está asegurada la simetría entre las recompensas para quienes cumplan prestamente con las reglas acordadas y las penalidades para quienes no lo hagan?

Lo que sigue no pretende dilucidar del todo estas interrogantes, sino tan sólo abordar algunas dimensiones del problema desde una perspectiva interregional y sectorial, con la intención de ofrecer elementos para una elaboración más exhaustiva.

A continuación se examina, primero, el tema general de la convergencia; luego se pasa revista a los alcances de la "replicabilidad" de las mejores prácticas de gestión productiva y de políticas en el contexto de condiciones iniciales y desafíos estratégicos dispares; finalmente, se evalúan las incertidumbres y asimetrías que plantea la cuenta regresiva hacia el año 2000 en el terreno específico de las MIC, desde una perspectiva interregional y sectorial.

\section{II}

\section{Verificación de hipótesis sobre la convergencia de los niveles de productividad e ingreso}

La formulación de hipótesis y predicciones sobre la convergencia entre países de los niveles de producti-

cal y de contención de la demanda agregada, en el caso de Malasia se está haciendo en prevención de un acuerdo con el Fondo Monetario Internacional (FMI). Esto incluye la reciente presentación a la OMC de un programa de liberalización en el sector financiero. Por otro lado, Tailandia está retrasando su programa de desgravaciones arancelarias en el sector químico. En el caso de Indonesia, el último acuerdo con el FMI elimina las exenciones impositivas al proyecto Timor. En el cono sur americano, Chile ha anunciado una reducción del nivel arancelario promedio del 11 al $8 \%$ a partir de 199S, simétrica al aumento del $3 \%$ en el arancel externo común del 12 al $15 \%$ por tres años, decidida por el MERCOSUR. Aunque The Economist (1997, sección "The Americas") adopta una actitud inusualmente tolerante y benigna frente a este aumento, la Unión Europea ya ha expresado su preocupación al respecto (véase las declaraciones de A.M. Campogrande, Administradora Principal de Relaciones Exteriores de la Unión Europea, en Estrategia, 5 de diciembre de 1997).

3 "A pedido de parte, el Consejo de Comercio de Bienes puede extender el período de transición para la eliminación de las MICs...para un...Miembro...que demuestre dificultades particulares en la puesta en vigor de las provisiones de este Acuerdo. Al considerar tal solicitud, el Consejo...tendrá en cuenta las necesidades del desarrollo individual, financieras y comerciales, del Miembro en cuestión." (Párrafo 3, Art. 5, sobre notificación y acuerdos transitorios del Acuerdo sobre las MIC). vidad e ingreso se funda en la teoría del crecimiento económico, cuyos cimientos conceptuales básicos fueron sentados por los economistas clásicos y sus sucesores directos. Entre tales cimientos se incluyen el papel de los rendimientos decrecientes en la acumulación de capital físico y humano, la relación entre ingreso per cápita y tasa de crecimiento demográfico, los efectos del progreso tecnológico sobre la especialización del trabajo y la influencia del poder monopólico en el progreso tecnológico. ${ }^{4}$

Los modelos neoclásicos de crecimiento predicen una convergencia condicional según la cual cuanto menor es el nivel inicial del PIB real per cápita de un país en relación a su nivel de largo plazo (steady state), más alta será su tasa de crecimiento a raíz de un mayor rendimiento relativo de la inversión. Esto siempre que se haga abstracción de las diferencias entre países en

\footnotetext{
${ }^{4}$ Se incluyen, además de Adam Smith, David Ricardo y Thomas Malthus, economistas de este siglo como Frank Knight y Joseph Schumpeter.
} 
tasas de ahorro, niveles iniciales de capital humano, crecimiento demográfico, políticas gubernamentales y cambio tecnológico.

La teoría neoclásica del crecimiento caducó como campo de investigación a principios de los años setenta por carecer de relevancia empírica. A partir de entonces, la investigación macroeconómica se concentró en las fluctuaciones de corto plazo. La teoría del crecimiento renació hacia mediados de los años ochenta, cuando se inauguró un período de gran efervescencia intelectual en la materia. ${ }^{5}$

¿A qué conclusiones llega la investigación empírica disponible sobre las hipótesis acerca de la convergencia de los niveles de productividad e ingreso? Una comparación de la evolución del PIB real per cápita entre 129 países durante 1960-1990 indica que el nivel de dispersión ha aumentado: el país más adelantado de la muestra, los Estados Unidos, pasó de un PIB per cápita 39 veces superior al del país más rezagado (Etiopía) en 1960, a uno 65 veces superior en 1990. A la tasa histórica de crecimiento del Japón entre 1890 y 1990 (2,75\%), Etiopía podría acercarse hacia el año 2149 al nivel de los Estados Unidos en 1990. A la más moderada tasa histórica de este último país $(1.75 \%)$, lo lograría hacia el año 2236 (Barro y Sala-i-Martin, 1995, p. 3).

\footnotetext{
${ }^{5}$ La emergencia de la nueva teoría del crecimiento señala una ruptura de proporciones copernicanas con la tradición (y la irrelevancia) de los supuestos neoclásicos. En lugar de mercados perfectos se postulan mercados imperfectos, la abundancia de bienes públicos sustituye a la posibilidad de apropiación total privada, los rendimientos crecientes reemplazan a los rendimientos decrecientes y el cambio tecnológico endógeno al cambio tecnológico exógeno. En estas condiciones, y particularmente en presencia de la apropiación monopólica de los frutos de la inversión en investigación científica y tecnológica, la tasa de crecimiento no tiene por qué necesariamente disminuir a altos niveles de acumulación de capital por persona ocupada, en tanto que se torna importante la influencia de las políticas gubernamentales en la tasa de crecimiento a través de su impacto en el grado de apertura de la economía, la tasa de ahorro, el nivel educativo, la difusión de tecnología, etc. De este modo, la teoría del crecimiento, si bien aún carece de muchas respuestas, se reconcilia con la realidad y vuelve a alimentar la indagación empírica y a ser realimentada por ella. En particular, permite reconsiderar las predicciones relativas a la convergencia condicional. En una interpretación agnóstica del aporte de las nuevas teorías del crecimiento, Nelson (1997) señala que mucha de la modelización formal de estas teorías tiene lugar a expensas de su pertinencia y consiste en la adopción tardía de comprobaciones empíricas ya existentes. Por ejemplo, se supone previsibilidad perfecta (o una distribución de probabilidades de ocurrencia de eventos futuros correctamente especificada), se ignoran las diferencias entre los modelos de gestión empresaria y organización institucional y se hace a un lado el tema del aprendizaje tecnológico. Una importante razón metodológica de lo expuesto es que los modelos respectivos procuran no distanciarse de los cánones de la teoría del equilibrio general.
}

La tasa anual media de crecimiento del PIB real per cápita entre 1960 y 1990 para una muestra de 114 países fue del 1.8\%, con la República de Corea (6.7\%) en un extremo e Iraq (-2.1\%) en el otro. Otros 16 países incluidos en la muestra, en su mayor parte de la región subsahariana, también exhibieron tasas de crecimiento negativas. En otras palabras, el país representativo de esa región precisó 30 años para crecer 1.3 veces, contra 7.4 veces en el caso de la República de Corea (Barro y Sala-i-Martin, 1995, pp. 3-4).

En síntesis, la hipótesis de que cuanto más rezagada es la posición inicial de un país en términos del PIB real per cápita mayor será su tasa de crecimiento no ha sido verificada, excepto en el sentido condicional definido más arriba. Pero aún en tal escenario hipotético de un mundo homogéneo excepto en nivel de crecimiento, el ritmo de convergencia sería de una lentitud tal que la eliminación de la brecha entre el PIB real per cápita corriente y su nivel de largo plazo demandaría un mínimo de 70 años.

En el caso particular de América Latina, las estimaciones disponibles indican que la brecha entre la productividad total de los factores en América Latina, por un lado, y en las economías avanzadas y de industrialización reciente del Asia oriental, por el otro, se ensanchó sensiblemente desde la posguerra, en especial desde mediados de los años sesenta (Ramos, 1997). Tampoco se verifica convergencia entre los niveles de productividad laboral del sector manufacturero en América Latina y en los Estados Unidos durante 19701994, salvo en el interregno 1973-1982 (Benavente, Crespi, Katz y Stumpo, 1996).

Una incursión en las dimensiones de la divergencia más allá de las hipótesis de la teoría del crecimiento lleva a distinguir entre convergencia económica (esto es, niveles de productividad y estándares de vida) y convergencia institucional. Esta última se refiere a las múltiples configuraciones de la relación entre mercado, política pública y asociaciones y jerarquías públicas y privadas. Tales relaciones varían ampliamente en los mercados de factores y de productos. La convergencia, en este sentido, consistiría en una creciente afinidad de formas institucionales y de respuestas a desequilibrios políticos, sociales y económicos de origen externo o interno.

La viabilidad de desempeños económicos comparables en el largo plazo puede ser compatible con configuraciones institucionales bien diferentes (véase más adelante la distinción entre convergencia macro y convergencia micro), de modo que el ámbito de heteroge- 
neidad en lo institucional es considerablemente más amplio que en el sentido estricto de las variables estilizadas de la teoría del crecimiento.

$\mathrm{Si}$, como se vio, la hipótesis de la convergencia económica es de difícil verificación, mucho más lo es la hipótesis de la convergencia institucional, la que se ve notablemente debilitada por la persistencia de las especificidades nacionales (Boyer, 1996).
El debate sobre la convergencia remite, en última instancia, a la rivalidad entre diversas civilizaciones y su influencia sobre la configuración del orden mundial en términos de grado de diversidad admisible. Las relaciones entre universalidad y especificidad son objeto de una controversia secular hoy renovada por las transformaciones posteriores a la guerra fría (véase Huntington, 1997, especialmente el cap, 12). ${ }^{6}$

\section{III}

\section{La "replicabilidad" de las mejores prácticas en el contexto de las condiciones iniciales} y la disparidad de desafíos estratégicos

En contraste con la hipotética convergencia hacia mejores prácticas de desempeño productivo y de políticas como resultado de la globalización, en los últimos decenios se ha venido registrando una creciente diferenciación dentro del mundo en desarrollo. Además de generar una gradación entre ganadores y perdedores, esa diferenciación también plantea dilemas y desafíos de política cuya disparidad relativiza en gran medida la posibilidad de transferir y reproducir experiencias. La diversidad de condiciones iniciales que exhiben jos países en desarrollo y las economías en transición dotan a los desafíos confrontados de un alto grado de especificidad.

Con la sola intención de esbozar la naturaleza del problema, en el recuadro 1 se muestra la disparidad de desafíos estratégicos que enfrentan cuatro categorías de países, a saber: i) economías de reciente apertura (esto es, en tránsito desde estrategias de sustitución de importaciones hacia economías abiertas e integradas al mercado mundial); ii) países de industrialización exitosa (los del Asia oriental y sudoriental); iii) economías en transición (ex economías de planificación centralizada), y iv) países de menor desarrollo económico relativo (el grupo conformado por las varias docenas de países más rezagados). Sin perjuicio de que haya importantes contrastes intragrupales desde los puntos de vista histórico, geográfico, económico, social e institucional (por ejemplo, el avance hacia la convergencia es más acelerado entre las economías en transición centroeuropeas que están ingresando a la Unión Europea que entre sus pares del Asia central), las diferen- cias de los desafíos de política entre estas cuatro categorías de países han adquirido proporciones históricas, esto es, asociadas a estadios de desarrollo casi tan distintos como los que median entre ellas y los países desarrollados. $^{7}$

Así, por ejemplo, en un extremo del espectro se encuentran los países que han logrado eliminar en el curso de pocos decenios buena parte de los obstáculos que se oponían a la convergencia de ingresos y productividad con el mundo desarrollado y, en el otro, aquellos que aún no logran encontrar la manera de librarse

\footnotetext{
${ }^{6}$ Huntington (1977, pp. 309 a 311) sostiene que quienes no reconocen las bifurcaciones fundamentales (entre civilizaciones) están condenados a ser frustrados por ellas, Más adelante explica que la diversidad cultural y de civilización desafía la creencia occidental, y sobre todo estadounidense, en la pertinencia universal de la cultura occidental. En lo descriptivo, esta creencia sostiene que los pueblos en todas las sociedades desean adoptar valores, instituciones y prácticas occidentales; en lo normativo, que los pueblos de todo el mundo deberían abrazar los valores, instituciones y cultura occidentales, por cuanto éstos incorporan el pensamiento más elevado, iluminado, liberal, racional, moderno y civilizado de la humanidad. Esta creencia adolece de tres problemas: es falsa, es inmoral y es peligrosa, afirma Huntington, quien concluye: el curso prudente para Occidente no es [copiando a Brutus] tratar de congelar los desplazamientos de poder sino aprender a navegar las corrientes, resistir las miserias, moderar sus aventuras y proteger su cultura. Las ideas de libertad individual, democracia política, orden legal, derechos humanos y libertad cultural han nacido en Occidente y la civilización occidental es valiosa no por su universalidad sino por su unicidad. (Traducción del autor). Lian y Oneal (1997) no han encontrado asociación sistemática alguna entre las diferencias culturales (étnicas, religiosas, lingüísticas) y el desempeño económico.

${ }^{7}$ Vẻase más detalles en Sercovich y otros, por publicarse, cap, 2.
} 


\section{Recuadro 1}

ESPECIFICIDAD DE LOS DESAFÍOS ESTRATÉGICOS EN MATERIA DE COMPETITIVIDAD, POR CATEGORÍA DE PAÍS

Categoría de país

Economías de reciente apertura

Países de industrialización exitosa

Economías en transición

Países menos desarrollados
Principales desafíos

Conjugar la apertura de la economía con la consolidación de la sustentabilidad competitiva

Llevar a cabo la transición hacia mejoras de competitividad basadas cada vez más en la innovación y el cambio técnico endógenos

Concretar una redefiníción fundamental del papel del Estado, revalorizar el capital humano, establecer un sistema de mercado, reestructurar la industria, modernizar los sistemas de gestión y reducir o eliminar importantes diferencias de ajuste estructural

Asegurar la viabilidad y sustentabilidad de los procesos de reforma, aumentando la capacidad interna de respuesta por el lado de la oferta mediante el cambio estructural, la acumulación de recursos y un sistema de incentivos consistente con el estadio de evolución de la estructura económica y social y con tas restricciones institucionales

Fuente: Sercovich y otros, por publicarse.

de las remoras del atraso relativo y absoluto. Los primeros están preocupados sobre todo de generar sus propias fuentes de innovación y cambio tecnológico endógeno y consolidar la marcha hacia actividades de valor agregado cada vez mayor. Los segundos deben aún experimentar con formas socialmente viables de progreso institucional y social, identificar actividades sostenibles que permitan acumular recursos en una economía abierta, instituir mercados y crear las capacidades necesarias para el cambio estructural. Las economías de reciente apertura y los países en transición van por andariveles totalmente diversos que entrañan cambios profundos de régimen económico, orientación estratégica y vinculación con el mercado mundial.

El gráfico 1 ofrece una ilustración sintética de lo dicho. Si se compara la evolución del ingreso per cápita de los países en desarrollo como porcentaje del ingreso per cápita de los países desarrollados durante el período 1960-1990, en términos de paridades de poder adquisitivo, se concluye que los países del Asia oriental han sido los únicos que han podido reducir la brecha, la que se mantuvo en China y se acentuó en Africa, América Latina y el Caribe, Asia del Sur y los países del Medio Oriente.

La variada gama de desafíos arriba reseñada, sobre la cual no nos extenderemos aquí, indica lo difícil que sería proceder con conjuntos homogéneos de políticas. ${ }^{8}$ Seńa ilusorio pensar que países que transitan por períodos históricamente tan diversos en las carac-

${ }^{8}$ Véase Sercovich y otros, por publicarse, especialmente la parte III.
GRÁFICO 1

¿Convergencia?, 1960-1990

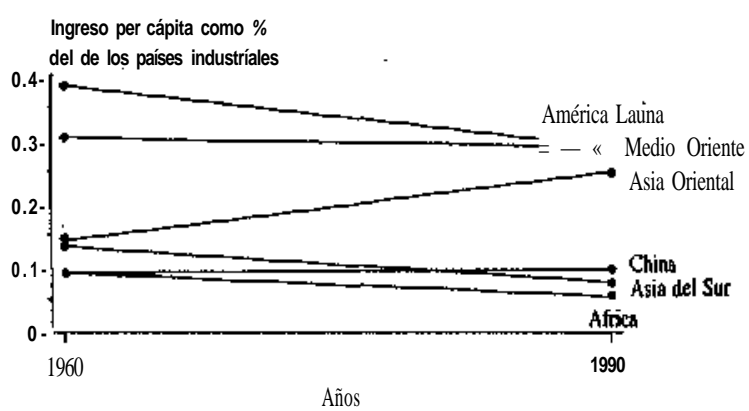

Fuente: Summers y Heston (1994): Penn World Tables, versión 5.6.

terísticas y tiempos de su evolución institucional, social, económica, tecnológica y educativa, pudieran converger en sus políticas tras unos pocos años.

Ante el supuesto de que puedan existir senderos homogéneos, políticas análogas y lineamientos estratégicos similares para la conducción de estos procesos de cambio tan diversos, las dudas aumentan al observar que, aun entre los países miembros del denominado "club de la convergencia" (los más desarrollados), hay sustanciales disparidades que obstruyen la posibilidad de reproducción recíproca de sus mejores prácticas respectivas. El recuadro 2 ofrece algunos ejemplos al respecto.

Es umiversalmente reconocido que los principios de la producción magra (lean production), originados en el Japón, significaron un enorme progreso respecto del fordismo tradicional, a tal punto que este tipo de 


\begin{tabular}{|c|c|c|}
\hline \multicolumn{3}{|c|}{$\begin{array}{l}\text { PRODUCCIÓN MAGRA, CAPACITACIÓN Y FORMACIÓN PROFESIONAL, Y GESTIÓN EMPRESARIA: LOS LÍMITES PARA } \\
\text { REPRODUCIR LAS MEJORES PRÁCTICAS ENTRE LOS MIEMBROS DEL "CLUB DE LA CONVERGENCIA" }\end{array}$} \\
\hline Mejor práctica y su origen & Principales atributos en el país de origen & Dificultades para su aplicación en otro ámbito \\
\hline $\begin{array}{l}\text { 1. Producción magra } \\
\text { (Japón) }\end{array}$ & $\begin{array}{l}\text { - Descentralización de la responsabilidad, } \\
\text { eliminación de "tiempos muertos" e } \\
\text { inducción constante del esfuerzo laboral } \\
\text { - Trabajo en equipo, calificaciones } \\
\text { polivalentes } \\
\text { - Motivación a través de! stress y la } \\
\text { "obligación recíproca" }\end{array}$ & $\begin{array}{l}\text { En Alemania: Las calificaciones son ocupacionales, } \\
\text { estandarizadas y polivalentes, en lugar de } \\
\text { generales y específicas al medio organizativo y } \\
\text { laboral de la firma, como en Japón. El que las } \\
\text { calificaciones sean polivalentes facilita la } \\
\text { movilidad laboral entre firmas independientes; el } \\
\text { que no lo sean favorece los mercados laborales } \\
\text { internos a la firma o conglomerado. Se da } \\
\text { prioridad a la discreción de los trabajadores } \\
\text { respecto de su propio desempeño y ethos laboral, } \\
\text { más que a la lealtad y devoción al empleador; e! } \\
\text { desempeño cuenta más que la antigüedad y el } \\
\text { trabajo en equipo descansa en calificaciones } \\
\text { individuales más que en capacidades grupales } \\
\text { como tales. }\end{array}$ \\
\hline $\begin{array}{l}\text { 2. Formación profesional } \\
\text { (Alemania) }\end{array}$ & $\begin{array}{l}\text { - Mecanismo eficiente de negociación } \\
\text { colectiva entre empleadores y empleados; } \\
\text { pocas presiones para alzar los costos } \\
\text { laborales unitarios; aversión de los sindicatos } \\
\text { a la inflación y el proteccionismo } \\
\text { - La capacitación es un componente explícito } \\
\text { de la negociación colectiva } \\
\text { - Los sindicatos responden al cambio técnico } \\
\text { demandando la recalificación de la mano de } \\
\text { obra y el aumento de la proporción de } \\
\text { trabajadores calificados en la fuerza de } \\
\text { trabajo }\end{array}$ & $\begin{array}{l}\text { En Francia; La tradición de control patronal y la } \\
\text { propensión a relaciones laborales contenciosas han } \\
\text { bloqueado la asimilación de las prácticas de } \\
\text { diálogo tripartito gobierno/empresas/sindicatos que } \\
\text { es vital para alcanzar consenso sobre programas de } \\
\text { capacitación y formación profesional efectivos y } \\
\text { sostenibles. }\end{array}$ \\
\hline $\begin{array}{l}\text { 3. Gestión empresarial } \\
\text { (Estados Unidos y Japón) }\end{array}$ & $\begin{array}{l}\text { - Minimización de los costos de transacción } \\
\text { (Japón) } \\
\text { - Minimización de los costos de coordinación } \\
\text { (Estados Unidos) }\end{array}$ & $\begin{array}{l}\text { En los Estados Unidos y Japón: Estos países } \\
\text { han discurrido por dimensiones particulares de la } \\
\text { dicotomía costos de transacción versus costos de } \\
\text { coordinación, de modo que poseen sistemas de } \\
\text { gestión empresaria que no son reproducibles } \\
\text { recíprocamente. Contrastes similares entre el Reino } \\
\text { Unido y Alemania han frenado el progreso hacia } \\
\text { una legislación europea común en la materia }\end{array}$ \\
\hline $\begin{array}{l}\text { Fuente: Basado en Berger } \\
\text { a Se aplica a trabajo } \mathrm{m}\end{array}$ & $\begin{array}{l}\text { (eds.), } 1996 . \\
\text { operaciones de ensamblaje. }\end{array}$ & \\
\hline
\end{tabular}

producción puede ser considerada sin lugar a dudas como una mejor práctica internacional digna de ser emulada. De hecho, emularla ha sido la intención de empresas en todo el mundo, particularmente en los países desarrollados, incluso Alemania. Sin embargo, como se muestra en el recuadro 2 para el caso alemán, las diferentes instituciones, prácticas y modalidades de funcionamiento social pueden restringir significativamente el ámbito de aplicación de los principios de la producción magra fuera del Japón.

Son bien conocidas, por otro lado, las dificultades con que han tropezado Francia y el Reino Unido al tratar de emular las eficientes prácticas alemanas en el terreno de la formación de recursos humanos y la capacitación profesional. De hecho, Francia ha fallado no sólo en sus intentos de reproducir las prácticas alemanas en materia de capacitación y educación, sino también en las esferas de la investigación científica y tecnológica, las relaciones laborales y la reestructuración industrial. La región de América Latina y el Caribe también ha tenido serios problemas para seguir el ejemplo del sistema dual de capacitación técnica que se aplica en Alemania a raíz, entre otras cosas, de una frágil formación educativa básica. La falta de tradición en materia de cooperación público-privada en este terreno ha sido otra razón de peso.

Examinemos también qué puede considerarse mejor práctica en materia de gobernabilidad de las empresas \{corporate governance). Las prácticas empresariales basadas en grandes grupos industriales que prevalecen en países como Alemania, Italia, Japón, la República de Corea y Suiza - tipificadas por el kereitsu 
japonés y el chaebol coreano- se traducen en mayor eficiencia en términos de menores costos de transacción merced a la existencia de contratos implícitos y un sistema de relaciones permanentes, estables y previsibles entre empresas. Por otro lado, el sistema anglonorteamericano posibilita menores costos de coordinación (agency costs) asociados a la separación entre propiedad y control. Lo que es ventaja en un sistema se convierte en desventaja en el otro. Puede notarse un análogo tipo de diferencias incluso dentro de la Unión Europea (con el Reino Unido y Alemania en las antípodas y Francia e Italia en una posición intermedia), lo cual ha conducido a la parálisis del cronograma para avanzar hacia una legislación empresaria común. Esto sugiere que puede existir no sólo una mejor práctica, sino una gama de mejores prácticas para atacar un problema dado y que la opciones se imbrican con los legados históricos, institucionales, de organización social y otros de cada país.

Si la existencia de procesos de convergencia más allá de las restricciones que impone la autonomía nacional está aún en debate en las esferas monetaria y fiscal (como bien lo ilustra la experiencia del lanzamiento del euro), el impacto de la globalización sobre los escenarios internos de política microeconómica acentúa las dudas, dado el mantenimiento de diferencias muy marcadas en las políticas, instituciones y prácticas nacionales. ${ }^{9}$ Las divergencias en el dominio microeconómico son mayores y más resistentes que las del dominio macroeconómico, por cuanto conciernen a instituciones, prácticas y tradiciones nacionales de profunda raigambre histórica. Esto lleva a rechazar la hipótesis de que la globalización de la economía mundial reduce a los Estados nacionales a la irrelevancia, la pasividad y la impotencia.

Las pruebas de éxito en la réplica de políticas microeconómicas e institucionales no son muy persuasivas (es posible que los fracasos en esta materia excedan a los éxitos). Las mejores prácticas que se citan a nivel microeconómico normalmente se refieren a cuestiones de eficiencia operacional. Empero, el núcleo de las estrategias empresariales y los respectivos lineamientos de política pública tienen que ver con opciones entre alternativas que son específicas al medio socioeconómico. El potencial de reproducción de las técnicas dirigidas a mejorar la eficiencia operacional, como el control de la calidad total o la competencia "basada en el tiempo", debe pasar por el test ácido de la adaptación de esas técnicas al contexto empresarial específico antes de verse materializado (Porter, 1997).

Los procesos de aprendizaje locales, la producción de bienes públicos, la formación de capacidades y la promoción del aprovechamiento de rendimientos crecientes a escala son esferas de la política nacional que ni siquiera los países más avanzados se sienten muy propensos a dejar en las manos del mercado, ya sean éstas visibles o invisibles.

Antes que de prácticas universalmente mejores, normalmente se dispone de gamas de mejores prácticas cuya adopción normalmente es hibridizada durante el proceso de adopción y adaptación a condiciones nacionales específicas.

\section{IV}

\section{OMC 2000: una perspectiva subregional y sectorial comparativa}

\section{El desafío}

El examen de los ritmos y estilos con que los países confrontan la cuenta regresiva hasta el $1^{\circ}$ de enero del

\footnotetext{
9 Así, por ejemplo, está aún por demostrarse si es posible concretar el acople de la ortodoxia alemana a nivel macroeconómico con el laissez faire angloamericano a nivel microeconómico. En relación a los países en desarrollo y las economías en transición, Rodrik (1996) ha señalado que el consenso respecto de lo que constituye una reforma estructural apropiada se basa en fundamentos teóricos y empíricos mucho más frágiles que el consenso sobre la necesidad de estabilidad macroeconómica.
}

2000, fecha en que finaliza el período de transición para el cumplimiento de las obligaciones contraídas con la OMC respecto a las MIC, arroja muchas luces sobre la disparidad que se observa en los enfoques de política microeconómica. De hecho, pareciera no haber consenso acerca de cuál es el significado preciso de ese período de transición. Cabe distinguir dos enfoques ai respecto.

Algunos países conciben ese período como uno de progresiva convergencia hacia la situación que deberá prevalecer el $1^{\mathrm{O}}$ de enero del 2000 , de modo de 
llegar a esa fecha con la casa en orden. Otros países, en cambio, lo visualizan como una carrera contra el tiempo; algo así como una última oportunidad para utilizar a fondo todos aquellos instrumentos de política que, a partir del año 2000 (2002 para los países de menor desarrollo económico relativo), les estarán vedados porque pasarán a ser considerados como malas prácticas y serán correspondientemente sancionados; lo que buscan tales países es ubicarse en la mejor posición posible en materia de aprendizaje tecnológico y competitividad manufacturera y tratar de dilatar los plazos recurriendo a mecanismos de excepción. ${ }^{10}$

Con estas diferencias de enfoque tiene que ver en cierta medida la proliferación de controversias en el seno de la OMC. Tan sólo entre enero de 1995 y setiembre de 1996 se plantearon ante ella 54 disputas vinculadas a 34 regulaciones cuestionadas, en contraste con 196 disputas que tuvieron lugar en los 47 años de existencia del GATT. Este aumento sugiere un elevado ritmo de actividad vinculado al acomodamiento al nuevo orden económico internacional, así como una percepción de la necesidad de vigilancia recíproca. El cuadro 1 da una idea de la distribución geográfica de los casos planteados ante la OMC por los países desarrollados respecto de prácticas de los países en desarrollo durante el período en cuestión.

Según el Banco Asiático de Desarrollo, sobre 25 disputas sometidas al mecanismo de resolución de controversias de la OMC originadas por países en desarrollo del Asia (ya sea como querellantes o como querellados), seis se vinculan con la industria automotriz mientras que las 19 restantes se distribuyen entre otros 10 sectores. La industria automotriz es, en efecto, uno de los sectores más sensibles en este terreno y uno de los que mejor ilustra la diversidad de ritmos y

CUADRO 1

Disputas planteadas ante la OMC por los países desarrollados, entre el 1 de enero de 1995 y el 18 de octubre de 1996

\begin{tabular}{lcc}
\hline & $\mathrm{N}^{\circ}$ de disputas & Porcentaje \\
\hline Países en desarrollo del Asia & 11 & 65 \\
Otros países en desarrollo & 6 & 35 \\
Total & 17 & 100 \\
\hline
\end{tabular}

Fuente: Banco Asiático de Desarrollo, 1997.

\footnotetext{
${ }^{10}$ La distinción no es tan nítida cuando las medidas son parte de conjuntos de política convenidos en el contexto de tratados de integración económica.
}

estilos de acomodamiento al nuevo orden económico internacional.

Este esbozo de la situación no puede cerrarse sin una referencia a China, cuya influencia se hace sentir profundamente en toda la región del Asia-Pacífico y más allá. Es improbable que China se atenga, salvo muy parcialmente y en el mejor de los casos, a las disciplinas de la OMC antes del 2010, si bien ya es la quinta potencia comercial del mundo y recibe el 35 a $40 \%$ de la inversión extranjera directa destinada a los países en desarrollo y las economías en transición (es poco probable que la ambigua situación de Hong Kong, miembro de la OMC y a la vez parte de China, ayude a simplificar o abreviar los plazos). Este hecho por sí solo plantea dudas vitales de que se logre la deseada nivelación del campo de juego para el año 2000.

\section{Las políticas de los países de la ASEAN hacia la industria automotriz}

Se estima que la industria automotriz mundial tendrá en el 2000 capacidad para ensamblar más de 210000 vehículos por día - hoy ensambla 178000 - y que más del 40\% de la capacidad ociosa emergente estará localizada en Asia (Deloitte \& Touche Consulting Group, 1997).

Como muestra el cuadro 2, dentro de la ASEAN Tailandia es el principal ensamblador, pues genera alrededor del $40 \%$ de la oferta actual. Le siguen Indonesia, Malasia, Filipinas y Vietnam, en ese orden.

Tailandia está aprovechando bien su posición privilegiada en cuanto a dimensión de mercado, infraestructura, experiencia acumulada y desarrollo de la industria de autopartes. Su proyecto es transformarse en la Detroit de la ASEAN y para ello aplica en el sector una política mucho más abierta que la de sus socios subregionales."

Casi todas las grandes empresas automotrices mundiales (y buena parte de sus proveedores, particularmente en el caso de las empresas japonesas) ya han instalado capacidad en Tailandia o lo están haciendo. La General Motors (GM) merece una mención especial, por cuanto ha negociado una inversión de 750 millones de dólares en Rayong para producir 100000 unidades anuales a partir de 1999 , un $70 \%$ de las cuales

\footnotetext{
${ }^{11}$ Se estima que Tailandia dispone de unas 600 empresas de autopartes, 200 de las cuales serían competitivas a escala internacional; muchas de ellas son firmas japonesas que trasladaron sus actividades a este país para evitar los elevados costos salariales del Japón y por la apreciación del yen.
} 
CUADRO 2

ASEAN: Distribución de la oferta automotriz en 1995 y proyectada al año 2000

\begin{tabular}{lrr}
\hline País & 1995 & $\begin{array}{c}2000 \\
\text { (proyección) }\end{array}$ \\
\hline Tailandia & 571000 & 850000 \\
Indonesia & 380000 & 600000 \\
Malasia & 296000 & 320000 \\
Filipinas & 129000 & 275000 \\
Vietnam & 15000 & 60000 \\
Total & 1391000 & 2105000 \\
\hline
\end{tabular}

Fuente: ONUDI.

serán destinadas a la exportación a partir del segundo año de funcionamiento. La GM espera que unos 30 de sus proveedores de autopartes la sigan a Tailandia u otros países próximos (desde el 2003 el comercio intraASEAN estará prácticamente liberado). La mayoría de esos proveedores serán los fabricantes europeos de autopartes de la Opel en Alemania. ${ }^{12}$

La GM se ha beneficiado de incentivos aplicados a inversiones en zonas rurales, la importación de maquinaria exenta de derechos por dos años, una exención impositiva sobre los ingresos de exportación por ocho años y una reducción del $50 \%$ durante los cinco años siguientes. Además, disfrutará de una reducción del impuesto sobre los ingresos durante 10 años hasta por el $25 \%$ de sus inversiones en infraestructura y $200 \%$ de sus gastos en transporte, electricidad y agua. También se le reducirán los derechos arancelarios que gravan ciertas materias primas. Además, el gobierno decidió financiar una inversión de 15 millones de dólares para el establecimiento de un centro educativo y de capacitación. Pero el rasgo más destacado e inusual del acuerdo entre la GM y el gobierno de Tailandia es que se convino la cancelación anticipada de las normas de contenido local para los automóviles. De manera que, tras haber sido tradicionalmente más abierta al capital extranjero que sus vecinos, de no mediar dilaciones Tailandia será a partir de 1998 el único país de la ASEAN en alistarse para cumplir sus compromisos con la OMC 2000 tanto en los plazos como en la forma. ${ }^{13}$

12 Casi dos tercios de las unidades producidas por la Toyota en países de la ASEAN tienen un contenido local del 40\% como mínimo. Esto incluirá productos que se intercambien a través del régimen preferencial común (AICO) que entrará en vigencia en el 2003 (JEI Report, 1997).

${ }^{13}$ GM utilizó bien la rivalidad intra-ASEAN por la captación de inversiones, en este caso entre Filipinas y Tailandia. El presidente Ra-
Indonesia y Malasia, en cambio, han acometido proyectos de desarrollo de un automóvil nacional - el Timor y el Saga, respectivamente- bajo regímenes de excepción fiscal y arancelaria y de subsidio financiero altamente selectivos. ${ }^{14}$ Estos regímenes permiten fijarles precios mucho menores que los de la competencia. Las regulaciones de contenido local gradualmente mayor son parte de estas políticas.

Malasia, más adelantada en este terreno, ha venido aplicando una inusual combinación de fuerte apoyo estatal y agresiva política empresaria de incorporación de tecnología. ${ }^{15}$ En 1996, Proton compró $80 \%$ del paquete accionario de. la Lotus de Inglaterra para tener acceso a tecnología de diseño y reducir así su dependencia de Mitsubishi, que posee el $8 \%$ de las acciones de Proton, Varios ingenieros de la Lotus trabajan ahora en la división de investigación tecnológica de Proton en el desarrollo de un sistema integrado de motor y caja de cambio. Proton, que está negociando asimismo la adquisición de Royal Begemann, productor belga de cajas de cambio, por 126 millones de dólares, constituye una de las piedras angulares del plan del Primer Ministro Mahathir de convertir a Malasia en un país industrializado en el 2020. La empresa exporta 18 a $20 \%$ de su producción anual a unos 30 países, incluidos el Reino Unido, Singapur, Francia, Indonesia, Chile y Australia, con márgenes próximos a cero.

El presupuesto de Malasia para 1997 contempla incentivos destinados a limitar las importaciones de bienes intermedios, partes y componentes por medio de la eliminación o reducción gradual de excepciones en la aplicación de derechos arancelarios e impuestos a las ventas. Frente a las restricciones vinculadas a los compromisos con la OMC, el gobierno se propone profundizar aceleradamente la estructura industrial y estimular el uso de insumos locales, especialmente bienes intermedios y de capital, a través del desarrollo de complejos industriales que abarquen desde los productos finales hasta las industrias y actividades de apoyo que ellos requieren; de este modo se busca reforzar las

\footnotetext{
mos había negociado personalmente con el titular de la GMel paquete de incentivos más atractivo jamás ofrecido por Filipinas: terrenos gratuitos por cinco años, cobertura de los costos de inversión en infraestructura, una escuela de capacitación de 20 millones de dólares y otros edulcorantes habituales. La oferta filipina fue de utilidad para la GM en su negociación para que Tailandia anticipara en 18 meses la abolición de sus reglas de contenido local.

${ }^{14}$ Véase la nota de pie de página $\mathrm{N}^{\circ} 2$.

${ }^{15}$ Víase un examen detallado de otro caso interesante de tipo similar en Sercovich, 1980.
} 
vinculaciones intrasectoriales, aumentar el valor agregado local y reducir las necesidades de importación. Las importaciones representan un $85 \%$ del valor de las exportaciones manufactureras, y las de bienes de capital cerca de la mitad del valor de la inversión. Toda importación de bienes de capital debe ser acompañada por programas de compensación vía exportaciones, incluyendo oferta de transferencia de tecnología (The Jakarta Post, 1996a). ${ }^{16}$

En Indonesia el gobierno ha reiterado su fuerte compromiso de desarrollar una industria automotriz independiente, favoreciendo la propiedad local, el desarrollo y uso de tecnología nacional y elevados porcentajes obligatorios de contenido local. Hasta ahora sólo ha calificado el proyecto Timor, que es llevado adelante por una empresa local asociada a KIA. Se trata de un sedán de 1600 cc y cuatro puertas, cuya producción local se iniciará en 1998 tras un primer año en que todas las unidades se importarán completamente terminadas para su venta local. El proyecto cuenta con total exención de los impuestos a las ventas y a los productos de lujo, lo cual permitirá vender el vehículo a precios alrededor de $50 \%$ más bajos que los de la competencia. El proyecto también tiene financiamiento subsidiado y hay una política de compras estatales que lo favorece (Business Times Malasia, 1996a, p. 2, y 1996b, p. 1).

La Unión Europea, los Estados Unidos y el Japón han acusado a Indonesia de violar tanto los principios de no discriminación y tratamiento nacional equitativo, como el acuerdo sobre las MIC, según el cual debería haber notificado su política en 1995 y no haber agregado nuevas regulaciones a partir del $1^{\circ}$ de enero de ese año, Al no haberse alcanzado un acuerdo entre las partes, la OMC ha instituido un panel para resolver la controversia, el que actualmente está trabajando. Se

\footnotetext{
${ }^{16}$ La política del gobierno está claramente enunciada en las palabras pronunciadas por el Primer Ministro Mahathir durante el lanzamiento del Séptimo Plan con vigencia hasta el 2000: "Algunos creen que la manera de reducir el déficit de balance de pagos es reducir la tasa de crecimiento. La respuesta simple es que hay que reducir las importaciones y aumentar las exportaciones. El contenido local de las exportaciones es aún bajo y debe ser elevado...Lo peor que se puede hacer es frenar el crecimiento aumentando la tasa de interés...La industria local debe producir todo lo necesario para la fabricación de los componentes del producto final. De este modo, los aumentos en las exportaciones no resultarán en aumentos similares de importaciones. Habrá importaciones, pero éstas estarán constituidas en gran medida por materias primas de bajo valor...El gobierno apoyará activamente la investigación tecnológica para aumentar el contenido loca! y capacitar a las empresas locales para fabricar bienes con sus propias marcas." (Traducción del autor).
}

especula que cuando el panel se pronuncie Indonesia ya estará más allá del punto de retorno en la materialización de su proyecto (aunque esto se ha tornado problemático a raíz de la crisis cambiaria y financiera desatada en julio de 1997). ${ }^{17}$ Es de destacar la disparidad que se observa entre las políticas genéricas y las selectivas en la ASEAN en general y en Indonesia en particular. Al mismo tiempo que reclaman contra ella las más grandes potencias comerciales del mundo en la actividad automotriz, Indonesia ha sido elogiada por el Banco Mundial como "el país con la economía más liberalizada del sudeste asiático", a raíz del conjunto de medidas de desregulación introducidas en junio de 1996. ${ }^{18}$ Sin embargo, tal desregulación no ha afectado barreras no arancelarias como las relativas a contenido local, autorizaciones de inversión, procedimientos de compras estatales y restricciones a la exportación de ciertos productos. La tasa media de protección efectiva actual para 269 categorías de bienes manufacturados se estima en un 52\%. Esta protección efectiva será reducida durante los próximos años por medio de bajas programadas en los aranceles nominales a fin de llegar a entre 0 y $5 \%$ en 1998 para una categoría de productos y al $20 \%$ en el 2000 para una segunda categoría (Business Taiwan, 1996).

El cuadro 3 informa sobre las condiciones relativas al contenido local en los países de la ASEAN y en otros países, con fines comparativos; muestra asimismo las reglas en la materia que han de ser cumplidas por las empresas y los porcentajes efectivos alcanzados o programados.

En síntesis, la situación se presenta como sigue:

i) En todos los países de la ASEAN, excepto Tailandia, se aplican políticas destinadas a aumentar progresivamente el contenido local durante los próximos años (esto es extensible también a China e India). ${ }^{19}$

\footnotetext{
${ }^{17}$ Las etapas de $e_{i}$ proceso de solución de controversias son: consultas (60 días), establecimiento del panel independiente, emisión del informe y decisión (entre 6 meses y medio y un año), aprobación del informe del panel (60 días), cumplimiento de la decisión o apelación (tres meses) y cumplimiento final (dentro de un período razonable acordado entre las partes). En la página de la OMC en Internet (http://www.wto.org) se podrán encontrar mayores detalles sobre las quejas interpuestas.

${ }^{18}$ Declaración de Dennis de Tray, director de la oficina del Banco Mundial en Jakarta, en The Jakarta Post, 1996b.

"Las políticas de contenido local en los países de la ASEAN no se limitan a la industria automotriz. Por ejemplo, Samsung se acomodó a los lincamientos del gobierno de Malasia de elevar el contenido local al $85 \%$ en la producción local de bienes de consumo electrónicos.
} 
CUADRO 3

Países de la ASEAN y otros páíses del Asia: Reglas y casos de contenido local en la industria automotriz ${ }^{8}$

\begin{tabular}{|c|c|c|c|c|}
\hline País & & Automóviles & Vehículos comerciales & $\begin{array}{l}\text { VAM per cápita de } 1993 \\
\text { (en dólares) }^{i 1}\end{array}$ \\
\hline Indonesia & (hasta) & (hasta) & $\begin{array}{l}30 \%^{\mathrm{C}} \\
40 \% \text { (Pickup Barkrie en } 3 \text { años) } \\
60 \%\end{array}$ & 167 \\
\hline Filipinas & & $40 \%$ & $45 \%$ & 198 \\
\hline Malasia & (hasta) & $\begin{array}{l}60 \% \text { d } \\
46 \% \text { : Kijang ASTRA (60\% en 1998) } \\
75 \% \text { (Saga Proton) } \\
58 \% \text { (City Honda) }\end{array}$ & $\begin{array}{l}45 \% \\
70 \% \text { (Pickups y camiones livianos ILOKOM } \\
\text { en } 3 \text { años) } \\
17 \% \text { (Land Cruiser Prado Toyota) } \\
51 \% \text { (Camiones Hicom/DRB/Isuzu en } 3 \\
\text { años) }\end{array}$ & 724 (1991) \\
\hline Tailandia & & $\begin{array}{l}54 \%^{e} \\
60 \% \text { (City Honda) } \\
70 \% \text { (Toyota Soluna) } \\
65 \% \text { (GM Opel, 1999) }\end{array}$ & $\begin{array}{l}72 \% \\
80 \% \text { (Pickup Ford/Mazda) }\end{array}$ & 607 \\
\hline $\begin{array}{l}\text { Vietnam } \\
\text { Taiwán } \\
\text { India }\end{array}$ & & $\begin{array}{l}30 \% \text { En } 10 \text { años }^{\mathrm{f}} \\
50 \% \text { J } \\
80 \% \text { (Fiat) } \\
70 \% \text { (Peugeot 309) } \\
90 \% \text { (Maruti } 800 \text { ) }\end{array}$ & & $\begin{array}{l}39 \\
3202 \\
59\end{array}$ \\
\hline China & & $\begin{array}{l}80 \%^{\text {b }} \\
90 \% \text { (Santana LX, 2.7\%, 1985) } \\
80 \% \text { (Santana 2000, 60\%, 1995) } \\
90 \% \text { (Jetta) } \\
65 \% \text { (Audi) } \\
85 \% \text { (Citroën 1988) }\end{array}$ & & 190 \\
\hline Rusia & & $65 \%$ (KIA en 5 años) & $65 \%$ (KIA en 5 años) & 628 \\
\hline Hungría & & $10 \%$ (Motores GM) & & 716 \\
\hline Botswana & & $20 \%$ (Hyundai desde 1998) & & 101 \\
\hline Argentina & & El régimen ha sido esencialmente liberalizado ${ }^{I}$ & & 1498 \\
\hline Brasil & & $85 \%$ Promedio actual, liberalización en curso & & $596(1991)$ \\
\hline México & & $36 \%$ (desde 1985$)$ & & 464 \\
\hline Turquía & & & $50 \%$ (Pickup KIA) & 630 \\
\hline Italia & & 75\% (Mitsubishi Pajero, 1999) & & 3503 \\
\hline Estados Unidos & & $75 \%$ (Toyota Camry) & & 4298 \\
\hline Reino Unido & & $90 \%$ (Nissan Primera) & & 2954 \\
\hline
\end{tabular}

Fuente: ONUDI,

a En todos los países de la ASEAN, excepto Tailandia, se ha programado un incremento progresivo de contenido local durante los próximos años.

Tailandia ha decidido abolir las reglas de contenido local en 1998

$b$ VAM - Valor agregado manufacturero.

c Dependiendo de la capacidad instalada.

d $30 \%$ para automóviles con más de 2851 ce, $45 \%$ para los que tienen entre 1851 y 2850 cc y $60 \%$ para los que no alcanzan los 1850 ce. El gobierno de Malasia ha advertido que excluirá del cálculo del contenido local aquellas partes y componentes con elevado contenido importado de subcomponentes.

c En este caso el contenido local no se mide de acuerdo al valor de las partes sino con un sistema de ponderaciones que asigna "puntos" a cada parte del vehículo de modo que la suma es 100.

f El contenido local actual es inferior al $10 \%$.

' Será eliminado cuando Taiwán ingrese a la OMC. Empero, tanto los aranceles como las restricciones no arancelarias en el sector automotriz continuarán por 8 años más (ver texto). Actualmente sólo se importan automóviles de los Estados Unidos y Europa. La tarifa es del $30 \%$ para automóviles y $42 \%$ para camiones.

h Desde 1995 las firmas automotrices con capacidad instalada en China deben garantizar un contenido local del $40 \%$ inmediatamente, del $60 \%$ dentro del segundo año y del $80 \%$ dentro del tercer año.

${ }^{\mathrm{i}}$ La participación del valor agregado local en el valor de la producción industrial cayó del 51\% en 1984-1985 al 35\% en 1994-1995. 
ii) Las normas de contenido local guardan escasa relación con los niveles de valor agregado manufacturero per cápita (gráfico 2). Esto significa que dichas normas no reflejan capacidades existentes —en cuyo caso pueden ser innecesarias, como sucede en muchos países industriales - sino las que se planean para el futuro. $^{20}$

3. Normas de contenido local y estrategia industrial en la ASEAN. Contrastes con el MERCOSUR

Las regulaciones de contenido local normalmente son parte de políticas de "indigenización", sustitución de importaciones, expansión de exportaciones, asimilación y desarrollo local de tecnología, desarrollo de capacidades e integración del espectro industrial. ${ }^{21}$ Por con- siguiente, vienen usualmente acompañadas por una panoplia de estímulos e incentivos arancelarios y fiscales complementarios, así como por programas especiales de capacitación, investigación y desarrollo, programas de localización industrial, etc. También son utilizadas como elementos de negociación frente a inversores extranjeros y socios comerciales.

Siguiendo el sendero señalado primero por el Japón y luego por la República de Corea, los países de la ASEAN aplican políticas destinadas a promover actividades de creciente contenido tecnológico y con mano de obra cada vez más calificada. De este modo confrontan la presión al aumento de los costos laborales unitarios y proyectan alcanzar el status de países industrializados en un par de decenios más. En Tailan-

GRAFICO 2

Industria automotriz: contenido local (CL) versus valor agregado manufacturero (VAM) per cápita en 1993

(Porcentajes y valores en dólares)

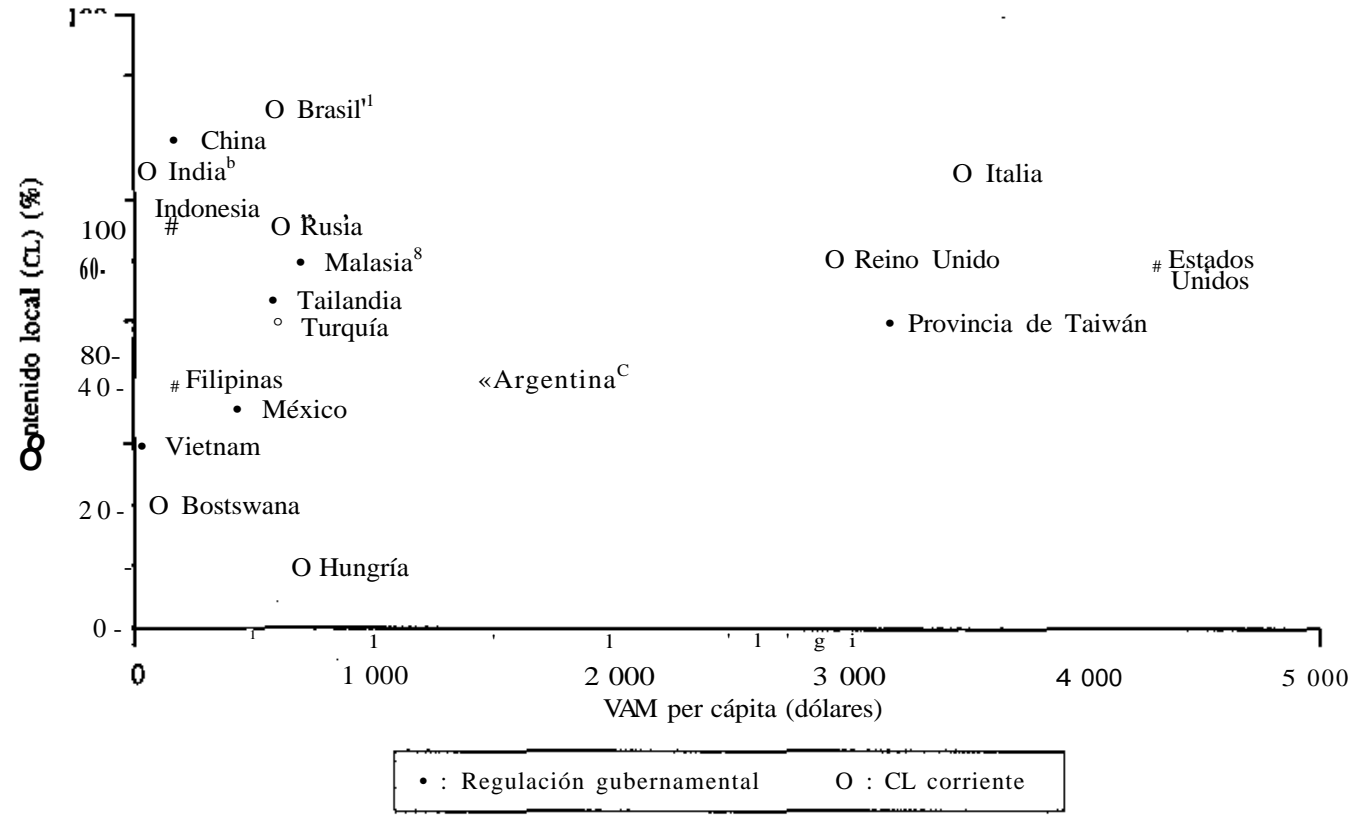

Fuente: ONUDI.

$\begin{array}{lllll}\text { a } & 1991 . \quad \text { b } 1990 . \quad c & 1992 .\end{array}$

\footnotetext{
${ }^{20}$ En los países industriales avanzados las normas de contenido loca son superfluas, excepto cuando se trata del establecimiento de reglas de origen con socios comerciales.

${ }^{21}$ Parece innecesario consignar el fuerte contraste entre este tipo de estrategia y aquélla tipo maquila, por ejemplo, con respecto a la
}

necesidad de dar prioridad, entre otras cosas, a un sistema educativo formal y técnico bien financiado y equipado, en condiciones de proveer trabajadores suficientemente capacitados. Sobre las vinculaciones entre aprendizaje local, cambio tecnológico y competitividad, véase Sercovich, 1988. 
dia, por ejemplo, el Instituto de investigaciones para el desarrollo ha informado que, por primera vez, en 1993 las exportaciones de productos basados en tecnología media y alta excedieron las de productos que hacen uso intensivo de mano de obra, y continúan desde entonces creciendo a una tasa mucho más elevada que estos últimos (Business Times, 1995, p. 5). El plan maestro industrial de hoy en Tailandia se basa en el desarrollo de complejos industríales como medio de profundizar la estructura industrial y completar la transición hacia una economía industrializada. El que no se hayan desarrollado polos industriales es percibido como una falla de mercado que hace necesario apelar a medidas de política para forzar a las firmas a aumentar el contenido local o para inducir el desarrollo aguas arriba, incluyendo redes de subcontratación tanto manufactureras como de servicios.

El continuo aumento resultante en el valor agregado como proporción del valor de la producción industrial hace marcado contraste con las tendencias prevalecientes en el MERCOSUR, donde se viene registrando un proceso opuesto, esto es, de desmantelamienlo de medidas destinadas a elevar el contenido local. Así, por ejemplo, en Argentina la participación del valor agregado local en el valor de la producción industrial se redujo del $51 \%$ en $1984-1985$ al $36 \%$ en 1994-1995. Una tendencia similar, aunque más moderada, ha comenzado a observarse en Brasil. ${ }^{22}$

\footnotetext{
${ }^{22}$ Argentina y Brasil se han comprometido a cancelar sus respectivos regímenes automotrices a fines de 1999. No obstante, la política automotriz brasileña originó fricciones con Estados Unidos, Japón, la República de Corea y la Unión Europea cuando el gobierno subió el arancel de importación de automóviles del 32 al $70 \%$ a mediados de 1995. Poco después ese arancel se redujo a la mitad para empresas establecidas a condición de que éstas exportaran un número equivalente de unidades y que el contenido local alcanzase el 60\% (40\% durante los primeros (res años en el caso de plantas nuevas). Japón se sintió discriminado por haberse mantenido hasta ese momento fundamentalmente en el negocio de importación. Posteriormente, el gobierno brasileño ofreció una cuota de importación de 40000 unidades por año con arancel del 35\% para empresas sin operaciones en Brasil. Si bien esto no satisfizo al Japón, fue considerado discriminatorio por los Estados Unidos. Este país presentó una queja ante la OMC el 10 de enero de 1997, alegando beneficios discrecionales conferidos a empresas del Japón, la República de Corea y la Unión Europea y violación de los artículos 1:1 y 111:4 del GATT 1994, el artículo 2 del acuerdo MIC y los artículos 3 y 27.4 del acuerdo sobre subvenciones y medidas compensatorias de la OMC. También se solicitó la cancelación de los beneficios aludidos en el artículo XXIII: I (b) del GATT 1994. Por su parte, la Unión Europea también presentó una queja el 7 de mayo de 1997 relativa a la leyes No. 9440 y 9449 del 14 de marzo de 1997 y decreto No. 1987 del 20 de agosto de 1996, alegando las mismas violaciones aludidas por la presentación de los Estados Unidos. El Japón retiró un recurso anunciado cuando el gobierno brasileño
}

Dicho contraste se manifiesta también a nivel agregado cuando se vincula el crecimiento de las exportaciones con el de las importaciones (gráfico 3). En lo que va corrido del presente decenio Argentina y Brasil claramente han aplicado políticas de apertura lideradas por las importaciones, a diferencia de los países de la ASEAN que últimamente han comenzado a sufrir problemas de balance comercial. Estos problemas, mucho menos graves que los del MERCOSUR (particularmente si se considera tan sólo el balance comercial del sector industrial), son la justificación de buena parte de las políticas actuales de sustitución de importaciones. Esto subraya los importantes contrastes que existen entre los patrones de industrialización de ambas regiones. ${ }^{23}$

En la ASEAN, tras haberse dado prioridad al desarrollo exportador manufacturero, actualmente le ha llegado el turno a la integración del perfil industrial (de difícil sincronía con las disciplinas de la OMC). El MERCOSUR siguió la secuencia inversa. De hecho, en la ASEAN se escuchan voces que advierten contra la introducción prematura de normas de contenido local que podrían limitar el desarrollo exportador, dada la baja competitividad relativa de las industrias locales de bienes intermedios y de capital. ${ }^{24}$

estableció un régimen de cuotas para compensar las ventajas que el régimen brindaba a firmas ya establecidas en Brasil. Este país evitó la conformación de un panel, como ocurrió en el caso de Indonesia, mediante una hábil gestión de diplomacia comercial. Brasil es actualmente el décimo fabricante mundial de autos y podría escalar al cuarto lugar hacía el 2000. Doce firmas están instalando plantas o completando decisiones para hacerlo (Renault, Toyota, Honda, Mercedes Benz, Volvo, Audi, Chrysler, Asia Motors, Kia, Daewoo, Hyundai y Peugeot). Hacia el año 2000 el MERCOSUR debería iniciar un régimen automotor común. La Asociación de Fabricantes de Automóviles (ADEFA) de la Argentina ha solicitado que esto se posponga y que continúen las reglas en vigor más allá del 1 de enero del 2000. El pedido obedece a que las firmas brasileñas estarían recibiendo mayores incentivos y protección y que, por lo tanto, el campo de juego no estaría nivelado. Los estados del norte brasileño eximen del pago de impuestos a las plantas radicadas hasta el 2010 , en tanto que el arancel es del $35 \%$.

${ }^{23}$ En este análisis es necesario no perder la perspectiva económica comparativa. No hay nada intrínsecamente perverso en compensar déficit en bienes industriales con superávit en bienes primarios. En promedio, los países del MERCOSUR disponen de una dotación de recursos naturales que como proporción de la dotación de mano de obra, especialmente mano de obra calificada, es mucho más alta que en los países de la ASEAN. Esto se expresa claramente en los respectivos perfiles de exportación. (Véase una comparación entre la ASEAN y el MERCOSUR en Sercovich y Peña, 1966; véase también Londero, Teitel y otros, 1997).

${ }^{24}$ Entre los países de la ASEAN, Myanmar es el que impone el nivel más bajo de protección arancelaria media (1:98\%) y Filipinas el más alto $(15.57 \%)$. Los demás países se encuentran en el rango del 5 a $10 \%$. Vemos así que ha habido una apreciable convergencia en los niveles de protección arancelaria media entre la ASEAN y el MERCOSUR. 
GRÁFICO 3

América Latina y Asia sudoriental (algunos países): Crecimiento de las exportaciones e importaciones, 1990-1996

(Tasas anuales de crecimiento en dólares corrientes)

Exportaciones

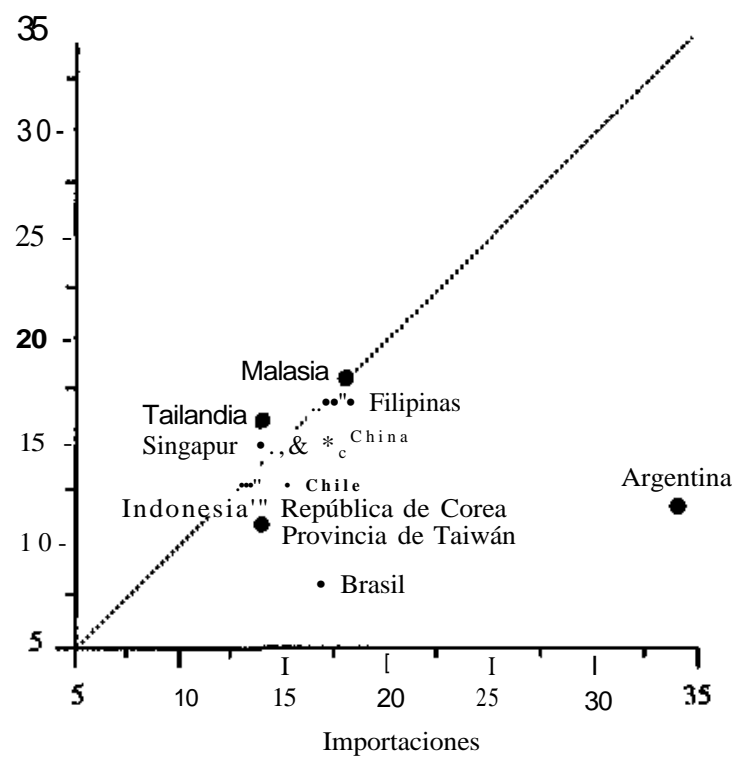

Fuente: ONUDI.

a En el caso de fas exportaciones de Brasil y Chile y de las importaciones de Indonesia y la provincia de Taiwán el período es 19901995.

En los últimos dos decenios, los países de la ASEAN han seguido los cánones ortodoxos de política más fielmente que ios países del MERCOSUR y lo han hecho más en lo macroeconómico que en lo microeconómico. Sin embargo, en los años noventa se ha observado una reversión importante. Mientras que en el MERCOSUR ha habido una fuerte inclinación hacia políticas más ortodoxas tanto a nivel macro como micro, en la ASEAN la disciplina macro exhibió una erosión en lo financiero, en tanto que se mantuvo un grado apreciable, aunque declinante, de heterodoxia a nivel micro. ${ }^{25}$ Estos desplazamientos parecieran haber tenido algún reflejo en el comportamiento de la inversión extranjera directa (gráfico 4). A partir de 1995 los países del MERCOSUR han estrechado considerablemente la brecha en la magnitud de las inversiones atraídas, que pasó de alrededor de $50 \%$ entre 1991 y 1994 al $18 \%$ en 1996.

${ }^{25}$ Véase más detalles en Sercovich y otros, por publicarse, cap. 6.
GRÁFICO 4

Inversión extranjera directa en cuatro países de la ASEAN $^{8}$ y en el MERCOSUR

Millones de dólares

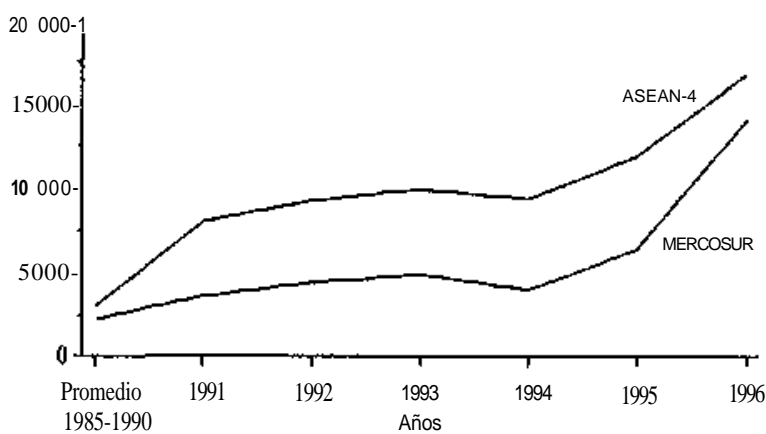

Fuente: UNCTAD, 1997.

* Indonesia, Malasia, Filipinas y Tailandia.

\section{La carrera contra el tiempo}

Tarde o temprano será preciso esclarecer la vinculación entre los compromisos contraídos con la OMC por los países en forma individual, y aquellos que deberán observar en su calidad de miembros de tratados de libre comercio e integración económica. Por ejemplo, mientras que los acuerdos relativos a las MIC regirán desde el año 2000, el Área de Libre Comercio de la ASEAN (AFTA) entrará en vigencia el 2003, el Área de Inversión de la ASEAN (AIA) en el 2010 y el programa de liberalización del comercio y las inversiones del foro de Cooperación Económica del Asia-Pacífico (APEC) en el 2020 para sus miembros en desarrollo. En los debates públicos y, más significativamente, en las decisiones empresarias de inversión y las condiciones correlativas acordadas con los gobiernos de los países de la ASEAN, parecieran tenerse mucho más presentes los plazos de la AFTA, la AIA y el APEC que los de la OMC. De hecho, como se verá más adelante, ha habido referencias explícitas a hacer converger los acuerdos con la OMC con los de los tratados regionales citados. Si así fuese, es improbable que ello conduzca a anticipar los plazos de estos últimos.

Excepto Tailandia, que como queda dicho ha decidido eliminar las reglas de contenido local en 1998, los gobiernos de los países de la ASEAN están sometidos a diversas presiones para aplazar su ajuste a las reglas de la OMC. ${ }^{26}$ Las empresas que llevan adelante

\footnotetext{
${ }^{26}$ En cierto modo tal sería ya el caso, puesto que ese proceso de adaptación no podrá tener lugar instantáneamente el 1 de enero del 2000 .
} 
programas plurianuales de inversión para concretar el progresivo aumento del contenido local con arreglo a las normas en vigor hasta el fin de 1999, corren el riesgo de confrontar importantes pérdidas en caso de que, abruptamente, el mercado se abra a competidores internacionales más eficientes. Es difícil que los gobiernos puedan desentenderse de las implicaciones sociales de este tipo de situación. No es descartable, por consiguiente, que procuren explotar ciertas áreas grises en el acuerdo de las Míe, tales como posibles excepciones y diferencias de interpretación. ${ }^{27}$

A partir del 2000 prácticamente el único sustituto de las normas de contenido local serán los aranceles (a muy bajos niveles). Por lo tanto, de lo que se trata es de tener para entonces una capacidad instalada que pueda operar con eficiencia suficiente como para sobrevivir con muy baja protección arancelaria. Este desafío se ha complicado considerablemente por la crisis desatada en la segunda mitad de 1997.

El sector privado filipino ya ha solicitado al gobierno que revise su compromiso con la OMC para liberalizar la industria automotriz en el 2000, con el objeto de dar a las empresas de autopartes tiempo suficiente para ajustarse a la nueva situación. Se pide que se mantengan las reglas de contenido local y las exigencias de balance de divisas aplicadas a la fabricación local de automóviles y ensamblado completo de unidades. También se solicita que el plan de liberalización sea pospuesto hasta el 2010, idea que ya viene circulando en otros países de la ASEAN (Business World, 1996, p. 12).

Significativamente, el Consejo de inversiones (ci) del gobierno de Filipinas ha hecho suya la propuesta del sector privado de que se extienda la implementación de la regla de contenido local para unidades completamente desensambladas (CKD) más alta del 2000, como parte de un esfuerzo por ayudar a la industria automotriz a alcanzar competitividad. El ci incluso apoyaría un aumento del contenido local, del $40 \%$ actual al $50 \%$ en el 2000 . A pesar de que esta medida debería ser conciliada con el programa de reforma arancelaria en curso, el ci la considera parte necesaria de una estrategia para desarrollar la industria de auto-

\footnotetext{
${ }^{27}$ La principal incógnita, desde luego, se refiere a China, país que está negociando importantes excepciones y plazos de gracia. China había ofrecido abolir sus barreras no arancelarias a la importación de automóviles en 15 años (en marzo último flexibilizó un tanto esta posición, ofreciendo en cambio $¡^{2}$ años).
}

partes local. ${ }^{28}$ Finalmente, el ci contempla la imposición de un impuesto específico del $7 \%$ a las unidades CKD, elevando el arancel sobre la importación de autopartes del $3 \%$ actual al $10 \%$. Estas propuestas forman parte del documento "Visión Automotriz Filipina 2020" que establece la estrategia del sector (Business Daily, 1997).

Aunque no se perciben señales claras con respecto a los plazos de la OMC, el gobierno filipino se ha declarado en favor de liberalizar los incentivos a la inversión extranjera dentro del sudeste asiático en el 2010 bajo el esquema AI A, como medida complementaria de la AFTA, con el objeto de elevar las inversiones intrarregionales. En el marco de la AFTA los aranceles bajarán a entre 0 y $5 \%$ en el 2003. La Cámara de Comercio e Industria de la ASEAN (la ASEAN-CCI), cuyo titular rotativo es actualmente un empresario filipino, está asimismo considerando establecer una regla de $50 \%$ de contenido local sobre los bienes de capital que provengan de fuera de la ASEAN.

Más allá de la esfera de la ASEAN, es ilustrativo el caso de la provincia de Taiwán: en sus negociaciones para el ingreso a la OMC, si bien está dispuesta a eliminar las reglas de contenido local, establecería medidas compensatorias destinadas a atenuar el impacto de esta medida y dilatarlo a través del tiempo.

El gobierno taiwanés aduce que, si aceptase las demandas de la OMC en su totalidad, las firmas automotrices locales tendrían que reducir su producción en un $60 \%$ y su participación en el mercado caería al $30 \%$, comparado con el $67 \%$ actual; que la producción de autopartes bajaría a la mitad y que tan sólo un $35 \%$ de las empresas de autopartes podría sobrevivir la eliminación de las reglas de contenido local. Considera asimismo que tan sólo tres o cuatro de las 11 firmas automotrices instaladas podrían sobrevivir como tales en un mercado liberalizado y que el resto se dedicaría a la distribución de automóviles importados. ${ }^{29}$ En sus negociaciones con la OMC el gobierno taiwanés procura resguardar la posición de sectores considerados importantes (como los de automóviles y bienes de consumo electrónicos), los que continuarán recibiendo una protección relativamente elevada. En esencia,

\footnotetext{
${ }^{28}$ El sector privado también propone que se eleve la exigencia de ingresos de exportación del actual $50 \%$ de las ventas totales a un $65 \%$ en el 2000 , medida que también sería inconsistente con los compromisos frente a la OMC.

${ }^{29}$ Declaración de la Oficina de desarrollo industrial, Ministerio de asuntos económicos, reproducida en The Jakarta Post, 1995, p,9.
} 
serían liberalizados tan sólo aquellos sectores que tienen un buen status competitivo, como los de productos informáticos y petroquímicos. Las autoridades taiwanesas han negociado concesiones comerciales bajo la forma de cuotas de importación de automóviles a aquellos países que acordaron apoyar su ingreso a la OMC bajo esas condiciones.

En efecto, la provincia de Taiwán ha negociado un acuerdo con Japón para su ingreso a la OMC, en el cual se establece un período de gracia de ocho años con posterioridad a ese ingreso, durante los cuales el mercado taiwanés se irá abriendo progresivamente a las importaciones de automóviles japoneses, que estuvieron prohibidas por 20 años. Se utilizará, asimismo, un sistema de "cuotas arancelarias", por el cual se podrán importar hasta 7700 automóviles pequeños en 1997, cifra que aumentará en 10\% anual hasta 1999, cuando el aumento cesará hasta que la provincia de Taiwán haya ingresado a la OMC. Una vez que esto último ocurra, la cuota anual será inmediatamente elevada a 10000 automóviles y a partir de allí crecerá a razón del $20 \%$ anual. Los automóviles importados dentro de la cuota serán gravados con un arancel del $29 \%$ el primer año tras el ingreso taiwanés a la OMC. El arancel bajará gradualmente hasta el $22.5 \%$ durante el período de gracia de ocho años. Las unidades que excedan la cuota serán gravadas con un derecho del $60 \%$. Tras el período de gracia, la restricción cuantitativa será eliminada y todas las unidades importadas estarán sujetas a un arancel uniforme de $22.5 \%$. Sin embargo, el requisito de contenido local de $50 \%$ para automóviles ensamblados localmente será abolido en cuanto la provincia ingrese a la OMC (Business Taiwán, 1997).

La provincia de Taiwán está negociando análogos acuerdos bilaterales con varios países a cambio del patrocinio a su ingreso a la OMC. Dado el fuerte impacto que sufrirán las empresas de autopartes a raíz de la eventual eliminación de los requisitos de contenido local (la producción podría caer hasta el 50\%), se están llevando a cabo enérgicos programas de automatización de procesos, elevación de la calidad de los productos, mejoras en la gestión, actualización de la tecnología de producción y mejoras de la comercialización. Con ello se espera retener un $75 \%$ del mercado local. Cabe finalmente destacar que, a pesar de haber sido la menos afectada de la región por la crisis financiera $y$ cambiaria de 1997, la provincia de Taiwán ha anunciado que pospondrá la liberalización del mercado de capitales más allá del año 2000 (International Herald Tribune, 19 de enero de 1998, p. 11).
GRÁFICO 5

ASEAN y MERCOSUR: Evolución estilizada del contenido local en [a industria automotriz, 1950-2000

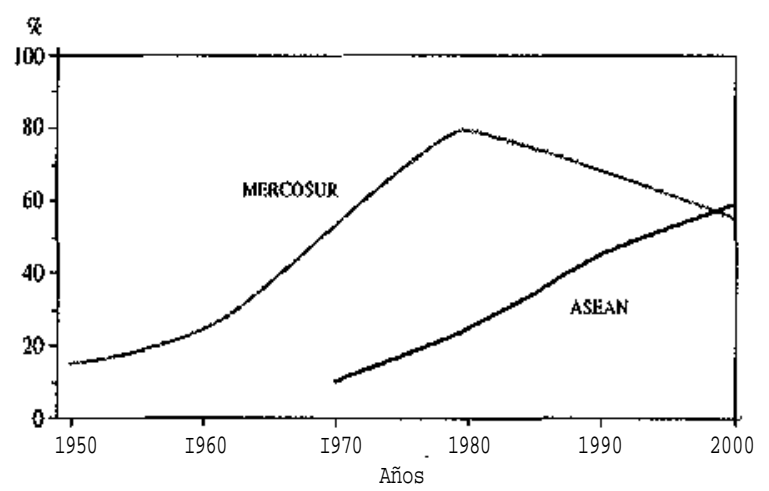

Fuente: ONUDI.

Por su ubicación en la curva de aprendizaje y sus orientaciones de política, los países del MERCOSUR encontrarían menos dificultades que los de la ASEAN para ajustarse a la OMC 2000 (gráfico 5). Parecería bastante difícil para la mayoría de los países de la ASEAN (así como para varios otros del Asia, entre ellos China e India) adoptar plenamente las disciplinas de la OMC en materia de MICs el 1 de enero del 2000, en virtud de la inercia de sus actuales políticas y procesos de inversión y su ingreso relativamente tardío en subsectores como la industria automotriz y la de bienes de capital. Esto podría plantear la necesidad de apelar a mecanismos de excepción en virtud de "dificultades particulares", contempladas por la OMC. Otra alternativa sería hacer que a nivel de la ASEAN haya exigencias de contenido local coherentes con las de la OMC vía su aplicación a nivel de la ASEAN (se sugiere, por ejemplo, $50 \%$ para los bienes de capital). Por otro lado, ninguno de los países del MERCOSUR se ha embarcado en políticas de desarrollo de "automóviles nacionales", como Indonesia y Malasia.

Los países de la ASEAN confrontan un desafío mayor: la competencia potencial de países continentales como China e India, que intentan desarrollar su propia industria automotriz. La respuesta más adecuada sería quizás la especialización intraindustrial a nivel regional. Pero hasta ahora tan sólo Tailandia se ha inclinado hacia un enfoque de carácter regional.

La cooperación industrial de empresa a empresa de la ASEAN (AICO) podría facilitar una respuesta a escala regional al estimular el aumento del contenido local a nivel regional con muy bajos derechos arance- 
larios recíprocos. Sin embargo, la AICO recién entrará en vigor el 2003, con lo cual parece difícil que se constituya en una respuesta efectiva antes del 2005 o el 2010. Uno de los problemas de la AICO es que cada país miembro aplica diferentes condiciones de excepción - por ejemplo, en materia de contenido localcuya armonización plantea problemas que no son simples de abordar, ${ }^{30}$

\section{V}

\section{Observaciones finales}

Pareciera no haber consenso respecto de qué constituye una mejor práctica, particularmente a nivel de políticas microeconómicas. Estas se rigen en gran medida por el legado institucional e histórico de cada país, y por la naturaleza de los objetivos perseguidos (que, a su vez, no pueden divorciarse de consideraciones geopolíticas).

Así por ejemplo, con diversos matices, los países de la ASEAN están decididos a emular las experiencias del Japón y de la República de Corea, de modo de unirse al "club de la convergencia" en un par de decenios. Sin embargo, este tipo de emulación no es exactamente el mismo que inspira las disciplinas de la OMC, por cuanto implica valorizar políticas destinadas a modificar sustancialmente la dotación inicial de recursos a lo largo del tiempo, más que adoptar dicha dotación como un dato inamovible para la configuración del futuro.

Bajo estas diferencias pueden identificarse dos paradigmas alternativos respecto del significado de la convergencia y de la nivelación del campo de juego. En uno, la nivelación es sinónimo de convergencia de políticas hoy. En el otro, denota convergencia en niveles de desarrollo mañana. El debate continúa.

(Traducido del inglés)

\section{Bibliografía}

Banco Asiático de Desarrollo (1997): Asian Development Outlook 1997-J 998, Manila.

Barro, R.J. y X. Sala-i-Martin (1995): Economic Growth, McGrawHill Advanced Series in Economics, Nueva York, McGraw Hill, Inc.

Benavente, J.M. ; G. Crespi, J. Katz y G. Stumpo (1996): La transformación del desarrollo industrial de América Latina, Revista de la CEPAL, $\mathrm{N}^{\circ}$ 60, LC/G.I943-P, Santiago de Chile, Comisión Económica para América Latina y el Caribe (CEPAL).

Berger, S. y R. Dore (eds.) (1996): National Diversity and Global Capitalism, Londres, Cornell University Press.

Boyer, R. (1996): The convergence hypothesis revisited: Globalization but still the century of nations?, S. Berger $y$ R, Dore (eds.), National Diversity and Global Capitalism, Londres, Cornell University Press.

Business Daily (1997): Bangkok, 5 de marzo.

Business Taiwan (1996): Taiwán, 26 de diciembre. (1997): Taiwán, 17 de febrero.

Business Tintes (1995): Kuala Lumpur, 6 de agosto.

Business Times Malasia (1996a): Malasia, 18 de octubre. (1996b): Malasia, 6 de noviembre.

Business World (1996): Bombay, 23 de diciembre.

De María y Campos, M. y F. Sercovich (por publicarse) :_Hacia una nueva visión de las políticas de desarrollo industrial y competitividad, México, D.F., Nacional Financiera, S.A. (NAFINSA).
Deloitte \& Touche Consulting Group (1997): The Automotive industry: Strategies and Priorities in a Global Environment, Londres.

Estrategia (1997): Declaraciones de A.M. Campogrande, Administradora Principal de Relaciones Exteriores de la Unión Europea, Santiago de Chile, 5 de diciembre.

Huntington S.P. (1997): The Clash of Civiliwtions and the Remaking of the World Order, New York, Touchstone Books.

International Herald Tribune (1998): Frankfurt, 11 de enero de 1998, p.11.

JEI Report (1997): Tokio, 7 de febrero.

Lian, B. y J.R. Oneal (1997): Cultural diversity and economic development: A cross-national study of 98 countries, 19601985, Economic Development and Cultural Change, Chicago, The University of Chicago Press, octubre, pp. 61-67

\footnotetext{
${ }^{30} \mathrm{La} \mathrm{AICO}$ es un régimen de tratamiento preferencíal común que permitirá a las firmas calificadas (las que operan en algún país miembro y tienen un mínimo del $30 \%$ de su capital en manos locales) disfrutar de aranceles del 0 a 5\% inmediatamente tras su entrada en vigencia en el 2003. Las empresas disfrutarán asimismo de incentivos no arancelarios y acreditación de contenido local regional. La AICO es un beneficio acelerado de ¡a AFTA y reemplazará a los esquemas de la ASEAN de empresas conjuntas industriales (ASEAN Industrial Joint Venture - AIJV-) y de complementación marca a marca (Brand-to-Brand Complementation - BBC-).
} 
Londero, E., S. Teitel y otros (1997): Resources, Industrialization, and Exports in Latin América, Londres, Macmillan.

Nelson, R. (1997): How new is new growth theory?, Challenge, vol, $40, \mathrm{~N}^{\circ}$ 5, Nueva York, M.E. Shaipe.

Porter, M. (1997): ¿Qué es estrategia?, Revista INCAE, vol. 10, N 1 , San José, Instituto Centroamericano de Administración de Empresas (INCAE).

Ramos, J. (1997): Política industrial y competitividad en economías abiertas, Desarrollo productivo, $\mathrm{N}^{\circ} 34, \mathrm{LC} / \mathrm{G} .1928$, Santiago de Chile, CEPAL

Rodrik, D. (1996): Understanding economic policy reform, Journal of Economic Literature, vol. 34, $\mathrm{N}^{\mathrm{O}} 1$, Nashville, Tennessee, American Economic Association.

Sercovich, F. (1980): State-Owned Enterprises and Dynamic Comparative Advantages in the Petrochemical Industry, Harvard Institute for International Development, Cambridge, Massachusetts, Harvard University.

(1988): Domestic Learning, International Technology Flows and the World Market, Ginebra, Organización Internacional del Trabajo (OIT).

Sercovich F. y otros (por publicarse): Competition and the world economy: comparing industrial development policies in developing and transition economies, Londres, Organización de las Naciones Unidas para el Desarrollo Industrial (ONUDI)/ E. Elgar.
Sercovich, F, y F. Peña (1966): From open regionalism to multilateralism: forging partnerships for global competitiveness in ASEAN and MERCOSUR, Viena, ONUDI,

Summers R. y A. Heston (1994): Penn World Tables, versión 5.6 (PWT 5.6) (Puede obtenerse del www.nber.org., en pub/pwt 56, University of Pennsylvania).

The Economist (1997): Londres, The Economist Newspaper, 22 de noviembre.

The Jakarta Post (1995): Declaración del Ministerio de Asuntos Económicos, Oficina de Desarrollo Industrial, Yakarta, Indonesia, 7 de febrero.

(1996a): Discurso del Vice Primer Ministro y Ministro de Finanzas de Malasia, Sr. Anwar Ibrahim, Yakarta, Indonesia, 21 de octubre.

(1996b): Declaración de Dennis de Tray, director de la oficina del Banco Mundial en Yakarta, Indonesia, $1^{\circ}$ de mayo

The Star (1997): Anuncio oficial del Primer Ministro, Datuk Seri Dr. Mahathir Mohamad, Kuala Lumpur, 30 de noviembre.

UNCTAD (Conferencia de las Naciones Unidas sobre Comercio y Desarrollo) (1997): World Investment Report 1997: Transnational Corporations, Market Structure and Competition Policy, Nueva York, Publicación de las Naciones Unidas, $\mathrm{N}^{\circ}$ de venta, E.97.II.D.10. 